\title{
CAN A TAKT PLAN EVER SURVIVE BEYOND THE FIRST CONTACT WITH THE TRADES ON-SITE?
}

\author{
Otto Alhava', Vili Rinne ${ }^{2}$, Enni Laine ${ }^{3}$ and Lauri Koskela ${ }^{4}$
}

\begin{abstract}
This study takes a critical look at Takt planning and takt control (TPTC) by analysing a successful case project. In the study, the digital system architecture and collected data are used for providing a process break-down and analysis in terms of waste and potential root causes. The paper shows how vulnerable the TPTC is for disruptions caused by a lead waste, making-do/task diminishment, and ad-hoc tolerance management. Based on the digital footprint of the project, an explanation is given why good results in terms of money, customer satisfaction, time and quality were achieved even though the takt was practically lost towards the end of the project. The results indicate that the excellent outcome of the project was not based on TPTC and steep learning curve. Instead, the results were achieved by exploiting the real-time situation awareness provided by the digitalised smart site and disciplined use of applications, as well as by a pragmatic approach to planning and leading work on-site. The validity of the results is limited as the conclusions are drawn based on only one TPTC project.
\end{abstract}

\section{KEYWORDS}

Takt planning and takt control (TPTC), job sequencing, work in progress, makingdo/task diminishment, tolerance management

\section{INTRODUCTION}

Takt Planning and Takt Control (TPTC) is booming in the construction industry, both in research and in the press. In the Finnish market, more than ten general contractors have already reported positive financial results gained with TPTC on construction projects. TPTC has also been tried out in FIRA Ltd, where two of the authors work. While the projects have been successful, the contribution of TPTC to the success is not immediately clear.

Graf von Moltke (1871), a Prussian field marshal and chief of staff of the Prussian Army, came into conclusion that no plan of operations extends with any certainty beyond the first contact with the main hostile force. Von Moltke would have been surprised about how precise his insight could have been a hundred and forty years later in the context of the construction industry. Based on the experience of the examined Takt project, the same weakness of exposing the pre-made plan with the reality also applies to the Takt plan and the first contact with the trades on-site. The TPTC is suggested to be the operating system of the construction industry combining

CTO, Fira Group Oy, Vantaa, Finland, +358 400 792493, otto.alhava@fira.fi

Production Engineer, Fira Oy, Vantaa, Finland, +358 44 3023471, vili.rinne@ fira.fi

PhD Candidate, Civil Engineering Department, Aalto University, enni.laine@aalto.fi

Professor, School of Art, Design and Architecture, University of Huddersfield, Queen St,

Huddersfield, West Yorkshire, HD1 3DU, United Kingdom. L.Koskela@hud.ac.uk 
successfully Lean culture, continuous planning and multilevel communication (Dlouhy et al., 2018). However, the pathogens of low productivity seem still to be lying dormant in the system and waiting an opportunity to come to light as an error (Love et al., 2009)

In view of this situation, this study aims to understand in detail the difference between the planned schedule and actual implementation of the tasks on-site in TPTC project by using the digital footprint provided by the mobile applications. The objectives for the study are: 1) provide visualisation for the planned schedule and actual implementation of the tasks, 2) provide analysis for the efficiency of the TPTC implementation, 3) identify the needed improvements for the use of digital footprint in the future TPTC projects, and 4) identify improvements TPTC implementation.

When the data from a case project was analysed first time in detail, the number of changes in the schedule as well as the delta between the initial schedule and the actuals was staggering, especially as the case project itself was considered to be successful and the throughput time was reduced more than $30 \%$ compared to a reference project. Similarly, the data revealed waves of defects, which were flooding the production process and finally changing the proactive planning of tasks to reactive management for fixing work. These findings raised questions for finding the pathogens and their root causes, which must be eliminated from the process before applying TPTC or any other modern flow-based methodology for increasing the productivity. The data also raised the question of why the project was managed and implemented so successfully even though the tolerance management failed. Similarly, it is clear, that the vicious cycle of waste generating more waste was present also though the TPTC was used.

The analysis of the data and the following interviews of participants suggested that there were too many problems in daily work, which were caused by the relatively loose tolerances of the installation of prefabricated elements or the tolerances of precast elements themselves. If compared to the installation tolerances of the kitchen furniture, there is a mismatch, which should be taken care of before starting the Takt. These problems were not apparent at the beginning of Takt phase, but they appeared as the work progressed to later the stages, and previous tasks were checked. This continuous appearance of waste reminds the vicious cycle of waste as Ohno (1988) describes in his work with the Toyota Production System (TPS). Even more severe was the tolerance problem, which was caused by slow and erratic drying of in-situ casted areas in apartments, as the installation of the laminated floor had to be rescheduled for reaching the moisture requirements of concrete floors before covering installation.

In addition to problems with tolerances and subsequent delays in installation times, which were recorded as roadblocks by trade partners or as re-scheduled tasks by main contractor's foremen, there was another type of root cause for quality deviations present. Based on data and reported rework, the definition of "done" was neither clear for those who were finishing their work nor to those who were checking and accepting the task as finished. Last Planner System (LPS) is used for supporting the implementation of tasks toward the planned accomplishments. Even though the TPTC was implemented in the case project and the project was completed in time, the last four weeks were mostly spent in fixing and finishing tasks, which were already reported done. Clearly, the project, with a successful outcome, did not triumph because of the TPTC or due to fact that the LPS was not used properly as a part of the TPTC implementation. 


\section{RESEARCH METHOD}

The site of the case project was digitised for providing connectivity to mobile devices and IoT sensors. The technical solution was developed based on experiences from the iCONS project (Zhao et al., 2018). The use of mobile applications provided a new source of data for the scientific work. Every transaction, change, assignment of the task in the scheduling app, inspection in the site by using the quality management app, or message in the site's Whatsup channel, leaved a trace to the event log of the particular system. This metadata was used during data mining and enrichment of data for this study, when the planned schedule, the actuals from the site and quality information were structured, merged, analysed and visualised. As depicted in Figure 1., all the applications used onsite created data and metadata in transactions and these data were collected to Fira's Open Data Platform (ODP). The metadata were used for providing visualisations used in this study. The data enrichment process was conducted in Fira's ODP by using the developed ontology of Takt production for combining data from Takt scheduling software, Fira SiteDrive and quality management software, Congrid and Congrid Lite. The developed ontology was essential in enriching the data for situation awareness tool, Fira InSite, as it provided the methods for visual interpretation of data in terms of business process, in the context TPTC.

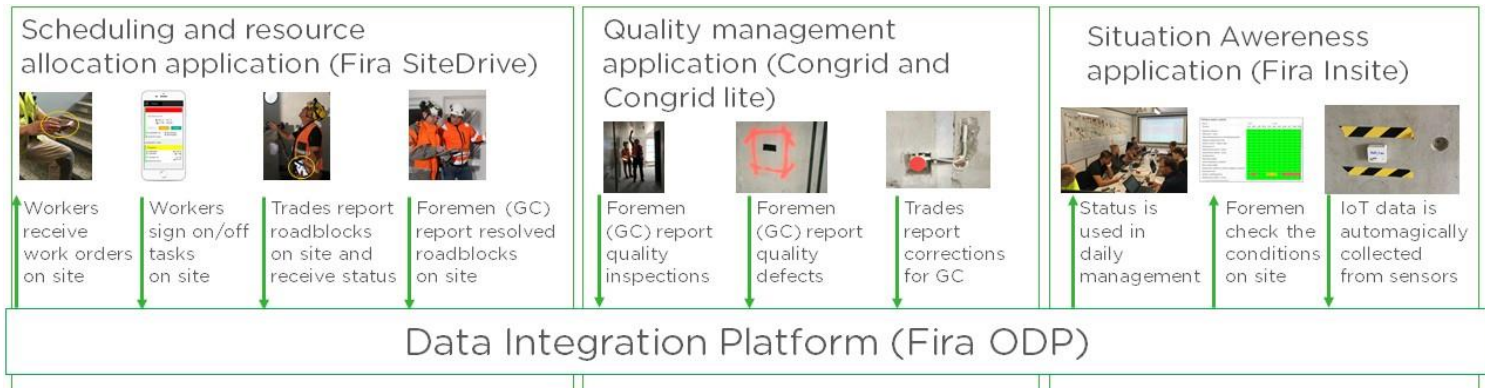

Figure 1 Situation awareness and visualisation of IoT sensor data required integration of point solutions data streams to the platform (Fira Open Data Platform) for providing real-time situation awareness to participants (Fira Insite)

\section{THE CASE PROJECT AND DATA ANALYSIS}

The studied case project consists of an internal work of a seven store residential building located in a recently built area in Helsinki. The building itself represents typical urban housing design in Helsinki, with 42 apartments from studios to three-room apartments. The delivery of the project was made through a design and build contract, which allowed the main contractor, Fira, to change the production into TPTC in a relatively late stage of the project and to narrow the scope of TPTC to be used for internal works of the apartments only. The decision to start using the TPTC on the project was made during the erection of the frame as the procurement of the remaining work was not finished. Half of the contracts for indoor works were signed before the decision for TPTC was made, and therefore the contracts were not tailored for TPTC although the contracting model included a clause on the general contractor's responsibility for providing the possible disambiguation to schedule. Thus, in a sense, the TPTC schedule was forced into use.

The main contractor focused on training and learning from the beginning of the indoor phase and provided resources for the site in this respect. The project personnel 
of the main contractor included three unexperienced foremen, a senior site manager and an adept site engineer. The personnel of trade partners were randomly selected, and reflected variation in skills as typical to the industry. None of the participants had previous experience or understanding of the TPTC. As there was a potential risk of failure when a new method is taken into use for the first time, the main contractor decided to focus on internal work and limited the TPTC cover only the apartments whereas the stairways, the bomb shelter, storage rooms, the sauna area, and the common facilities, were not included in the Takt schedule.

From the beginning of the project, the main contractor provided software development resources for the project team, with ambitions to develop Takt control tools for Takt project management. The site manager, foremen and selected trade partners participated in development and testing, which was conducted in six sprints during the first four weeks of the interior works. the results were published for the project after each sprint as situation awareness dashboards and tools. According to interviews, the most relevant tools for the project were 1) the main situation awareness dashboard (Fira InSite: Main View) and conditions monitoring dashboard. The Main View, depicted in Figure 1, was developed for and used on daily meetings as well as in daily planning and its functionality was owned by the site manager, who made the development decisions during sprints and controlled the features taken to the user interface.

Additionally, numerous other views were developed, e.g., user activity matrix for monitoring the learning curve of users during training and especially in daily management, conditions monitoring view (temperature, humidity, air pressure in each apartment based on IoT sensors), access control activity for logging presence of individuals on site for security purposes. Together with dedicated software applications for scheduling and quality management, the situation awareness main view established its role and position as a daily site management tool. The following use cases were identified in interviews: 1) project routine meetings: weekly Takt meeting with trades, the main contractor's internal weekly meeting for foremen and site manager, biweekly project meeting (main contractor and trades), 2) the site manager planning and control tool for managing all trades and own foremen, and 3) foreman planning and control tool for managing specific contracted work. Altogether, the intensive and disciplined use of the applications enhanced the management and leadership, as the decisions were made based on facts instead opinions, as typical in decision making.

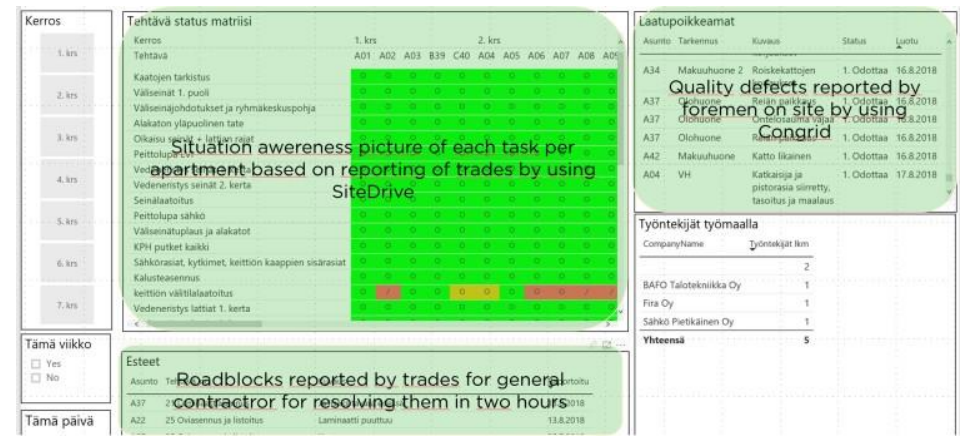

Figure 2. Situation awareness tool (Fira Insite), which was developed during the project for site manager and foremen for visualising the current status of tasks and roadblocks as reported by trades.

The use of real-time apps on-site also provided new features for daily management. As the scheduling app for trades provided a tool for allocating tasks in certain locations 
for a specific worker of a specific trade, the same app was used for reporting roadblocks, which were preventing worker from proceeding with the assigned task. This reciprocal channel was quickly tested and taken into use as the site manager realised the potential of receiving announcements from the site directly and immediately when the problem occurred in starting the task. The site manager gave a promise to the trade partners that every roadblock will be solved in four hours after reporting. Later, the site manager restricted the time to two hours, as it was essential, that the foremen of the main contractor reacted without anticipation to the alarms from the site.

\section{ORIGINAL TAKT PLAN}

From the first version of the Takt plan, the standard space unit was determined to be a single apartment even though the size of the apartment varies from one to three rooms and the floor plans of the same sized apartment were completely different depending on the location of the apartment. As depicted in Figure 3, the Takt schedule was a very straightforward and fluent flow of tasks in as-planned phase. Interviews revealed that there was only a very limited amount of dialogue with trade partners during the design of the Takt plan and the resulting schedule was merely given to trade partners as a contractual fact.

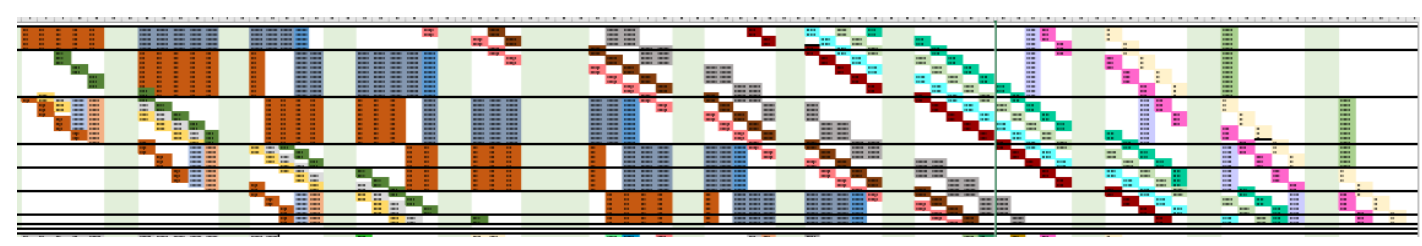

Figure 3 Original takt schedule was made in Excel and maintained manually in the site office. The method was found to be ineffective due to real-time and accessibility requirements of TPTC.

The production engineer used the methodology described by Frandson et al. (2013), for iteratively finding an optimal task order and minimising the throughput time. During the planning phase, logistics was not in focus, since movement of materials was mostly on the responsibility of trade partners.

\section{MOBILE TAKT PLAN AND REQUIREMENT FOR SITUATION AWARENESS}

Simultaneously with the manual Takt schedule, the project organisation started using Fira SiteDrive for maintaining the Takt plan and especially for allocating and updating the daily tasks for trade partners. The software also provided a mobile app to be used on site for trade partners' foremen and workers on site. The main contractor had also taken into use a quality management software, Congrid, which included a mobile app for quality inspections on-site and user interface for trade partners for receiving defect reports and tasks (Congrid Lite). The original intention was to introduce the apps and to have them to be used by every worker, but the utilisation rate was very low. The site manager made a decision that the use of apps was mandatory only for the main contractor's and the trades' foremen.

The main contractor was also developing a platform (Fira Open Data Platform) for integrating the data from point solution software and IoT on-site, to be used as raw data for data enrichment and business process analysis mandatory for providing situation awareness for participants. In Figure 3, the point solution software, use-cases and users are depicted for identifying the information flows and system architecture. 
The use of mobile applications for the scheduling, resource allocation and quality management, SiteDrive and Congrid, formed the digital footprint to the data integration platform, which was used for collecting raw data for this study. The visualisations presented in this paper can be interpreted by using the legend and colour coding displayed in Figure 4.

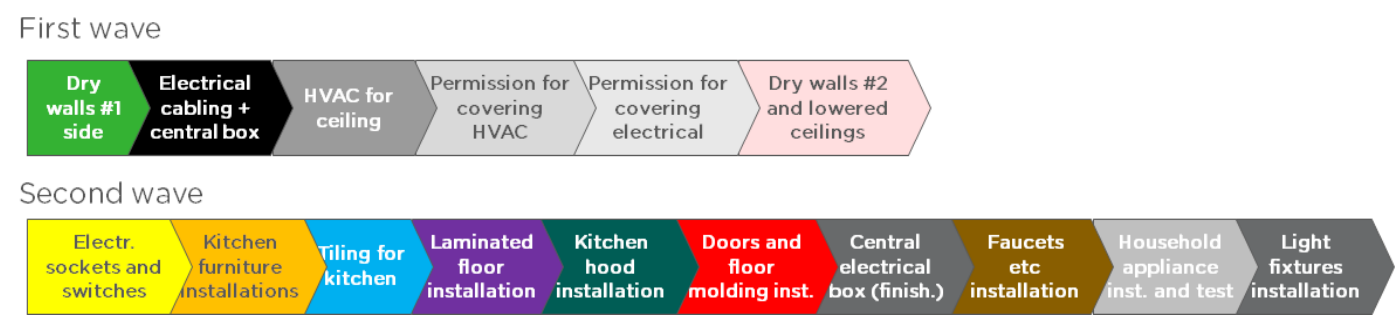

Figure 4. Work order of Takt schedule and colour coding for interpreting the Takt plan

The real nature of the whole Takt phase can be combined for visual inspection by adding the detected faults apartment by apartment to the as-build schedule. Firstly, the as-built schedule does not adhere to the original takt schedule. Instead, the duration of the completed tasks varies and the tasks are scattered into an order, which does not seem to follow any logic. Secondly, in Figure 5, the inspection rounds made by the foremen are added to the as-built schedule, indicating one or more faults detected per apartment. As the diagram shows, there were more than ten inspection rounds after the last reported completion of the last task. In twelve apartments, there were delivery problems with household appliances, and therefore the inspection date was delayed to the end of the project. When the faults are added to the same figure with as-build takt schedule, the actual progress of the project can be seen in same context. The amount of rework is now comparable with the takt schedule and deviations of task durations.

The data from the quality management tool reveals the number of faults in total at each phase of the project. Firstly, after the erection of the frame, there were 427 open faults, from which 366 were located to the apartments. The element installation trade made the levelling according to sub-contract, and the work was accepted. Unfortunately, more than 50 of these already fixed faults emerged at October in inspections, after the walls were finished and the laminated floors were installed. The reason for accepting faulty work was caused by misunderstood or misinterpreted tolerances. Similarly, all bathroom floors, which were cast in-situ, were re-plastered before installing the insulation due to inefficacious use of tolerances in contracts.

In the first week of July, the main contractor decided to restart the Takt procedure and implemented a thorough quality check to every apartment. The objective for the effort was to complete the situation awareness picture and to create two punch lists for all trades, one for tasks, which were blocking other tasks and second for standalone faults, i.e., faults which must be corrected, but there are not in priority. The number of faults in prioritised blocking fault list was relatively low, 155 pcs, 3 per apartment and the number of standalone faults was higher, 320 pcs. Faults were given to trades for fixing, although more than $1 / 4$ of them could not be originated, and therefore the main contractor had to take care of them. None of the fixing work was scheduled to SiteDrive or elsewhere. Instead, the lists were sent by using Congrid to trades leaving the digital signature for faults.

The second wave of Takt production should have started with installations of the floor lamination. Due to unexpected drying times, the order had to be changed from the 
planned, and all related tasks, especially the door installations and moulding had to be rescheduled as the drying had to be speeded up by using ventilation, dryers and compartmentalisation. The installed real-time condition monitoring system made the drying process foreseeable, as there were sensors in each apartment providing accurate measurements on humidity and temperature, which were visualised to the project team by mobile app, Fira InSite. From a process perspective, the drying of the concrete required proactive measures as the weather and humidity at the seaside was not favourable for the operation (humidity was between 60-70\% during working hours, temperature $25-33 \mathrm{C}$ ). The drying time was drastically reduced by using compartmentalisation in the apartments and dehumidifiers and air movers. Real-time monitoring of the conditions made it possible to the project team to take actions and control immediately whether the change in temperature and humidity was as planned.

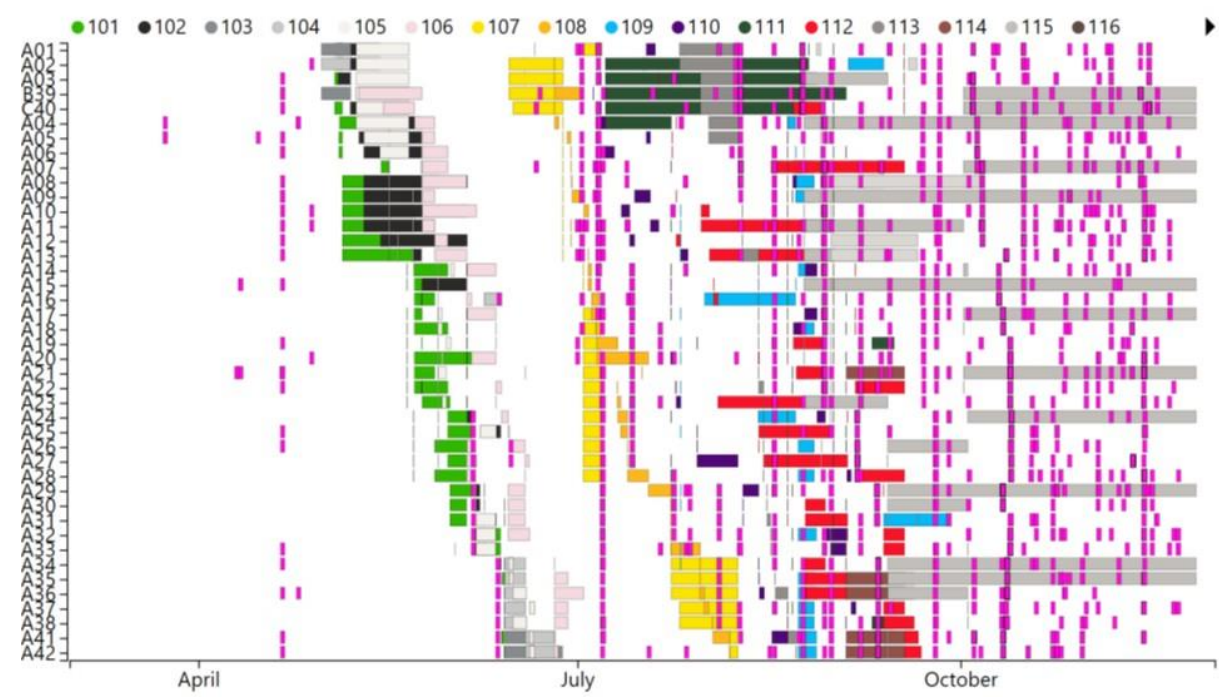

Figure 5. Actual tasks and their lengths in the Takt plan as reported on-site via SiteDrive app by foremen enriched with the data from quality control findings from Congrid

Based on data visualised in Figure 5, it is apparent that the Takt implementation in the case project was not producing results or benefits reported in Dlouhy et al. (2016) or Binninger et al. (2018). TPTC should specifically benefit the project when prefabrication and Takt planning are combined (Chauhan et al. 2018). TPTC should enhance the dialogue between participants and provide common understanding, which provides positive effects to the whole project (Dlouhy et al., 2018). The data provided by the quality inspections were used into the categorisation of sources of waste, as every fault was documented with pictures, a short written description, the location at the text, location in floorplan and the responsible trade partner.

The visualisation of the project cannot be fully understood or studied without a synthesis of individual phases. Figure 6 provides the first analysis for the Takt phase in the case project. Firstly, the main contractor tried to educate the trades for both using the Takt schedule and develop tools for efficient TPTC production (Ramp-up in Figure 6). Secondly, the main contractor managed to implement the TPTC for a short while (Takt production) and even (thirdly) thought there would be even more productive wave to come, and therefore a restart of Takt was planned and extra care for quality management was introduced (Restart). However, in the fourth phase, the tolerance problems surfaced (Tolerance Management), and as a result of them, the Takt plan was 
challenged. In the fifth phase, all the tasks in Takt were reported to be accomplished, but in reality, 2335 faults were detected, and the modus operandi of the project was changed from a proactive scheduling and resource allocation into reactive management of defect correction and punch lists (Quality Management).

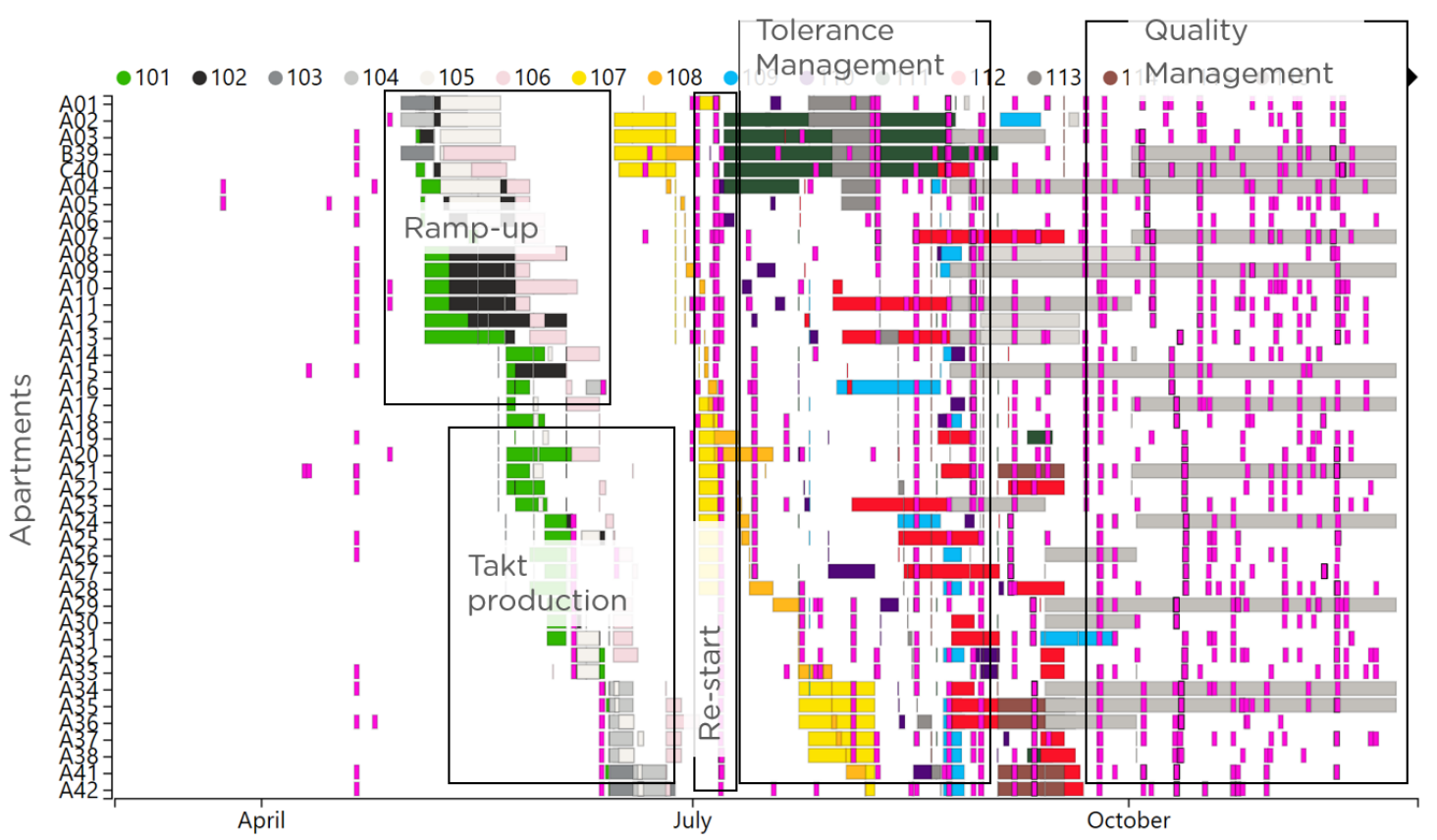

Figure 6. Suggested interpretation of phases moving the proactive TPTC implementation into reactive fault punch list management

Both tolerance and quality management phases can be examined by analysing the metadata from quality management software.

\section{THE LEAD ROOT CAUSE FOR CHALLENGES IN PROJECT: AD- HOC TOLERANCE MANAGEMENT}

In the case project, the first two weeks introduced problems with variation in required installation work hours of dry walls while the second wave of apartment construction work was seriously challenged by problems related to extended drying times. Both types of incidents required ad-hoc scheduling on-site, measuring the conditions per apartment continuously and adjusting the schedule accordingly. As can be seen from Figure 5., the Takt schedule and the cyclic order of work was heavily disturbed, and from the perspective of workers, the resulting working order was neither optimal nor easy to understand or remember. Instead, the lost regularity in order of work per floor required the foremen to continuously communicate changes and even intercept already started tasks for enhancing the daily flow.

Based on data from quality management app, Congrid, the tolerance management problems caused by the mismatch of precasting/installation tolerances and furniture tolerances, are surfacing when doors, furniture, doors, and moulding installations. There were not visible in after first wave, wherein the total of 420 faults were reported. Instead, the tolerance problems surfaced after the last task was finished and the previous tasks were approved.

Tolerances and the management of tolerances in the construction industry have 
received too little attention (Milberg and Tommelein, 2004). Recently, Talebi et al. (2016) argue that tolerance problems not only cause defects but also create chains of waste. These defects are present in the case project, as the tolerances of both concrete elements and their installation cumulated errors, which together were so severe that the following tasks had to be postponed for extra plastering work. Similarly, the whole installation of laminated floors, installation of floor moulding and doors had to be rescheduled due to prolonged drying times as the on-situ cast floors didn't meet the tolerances.

Based on data, 22 faults out of 141 faults were caused by ad-hoc tolerance management and remained through all inspections and corrections. Based on results, the holistic and continuous process for tolerance management was not in place in case projects, and the root causes, which Talebi et al. (2016) provided, 1) lack of standardisation, 2) poor workmanship, 3) lack of state of the art, 4) incomplete drawings and 5) inefficacious standards on tolerances, were all present and affecting to the TPTC process.

\section{LEAD WASTE IN THE PROJECT: MAKING-DO AND TASK DIMINISHMENT}

According to data from the case project, the quality management phase took four weeks of a total of six months during which the TPTC was conducted. In essence, the throughput time could be reduced by one month if the vicious cycle of waste could be removed. For further projects and for ensuring the productivity, it is vital that the TPTC implementation is changed and therefore the root cause allowing the waste cycle must be found, isolated and removed from culture, habits and process.

Koskela et al. (2013) have raised the question of origin and nature of waste in construction based on the finding that seven waste originally presented by Ohno and Shingo may not be relevant as such in the construction process. Koskela (2004) introduced the eighth waste, making-do, as a neglected but most relevant source of waste for the construction industry. According to Koskela, making-do refers to starting a task without all standard inputs or execution of task even though the availability of at least one standard input is ceased. Patton (2008) adds the definition of task diminishment to categories of waste, as actual customer value of the product will be less than expected due to the sub-optimised implementation of the individual task. Koskela et al. (2013) underline the prevalence of both making-do and task diminishment as they both cause further waste as well as serve the same purpose of absorbing variability as inventories in other industries and especially in car manufacturing.

Based on the data in quality management tool (Congrid) in the project (picture of the fault, location in floor plan, a short description, date and time, and responsible trade partner) it was possible to categorise further the last set of reported quality deviations and isolate the making-do/task diminishment as a root cause from other incidents. Examples of typical making-do incidents in the project were kitchen furniture installations with partially incompatible parts (3 pcs). Similarly, examples of task diminishment were the installation of the bathroom without adjusting the doors, installation of moulding without proper tightening/adjustment for ensuring proper fitting of the moulding or installation of light fixture without ensuring the correct positioning of the fixture, or for focusing the light to working surface on the kitchen. 
The quality management data reveals that seven of 42 apartments were handed over without faults. According to the project team, this result was considered to be better than the average on housing market. However, a thorough examination of data, including the results of customer complaints, the number of making-do/task diminishment faults was 45 out of a total of 141 faults. Keeping in mind that more than 2300 faults were fixed, but still, 45 faults remained in this category. The final 141 faults we categorised as an example case for finding making-do/task diminishment, and results showed that in the end of the project, the portion of making-do was $32 \%$ and task diminishment was $27 \%$, while the rest was either damaged or other types of faults. One can assume, that the same apply to all faults, which were detected during the project, and therefore the making-do/task diminishment was the lead waste.

\section{CONCLUSIONS}

The data from transactions of the project reveal the true nature of the TPTC implementation in the case project. Instead of completing the tasks without faults, the flow of the construction process let the subsequent task to be started. Instead of halting the line and understanding the root cause of fault and removing it, the work progressed and repeated causing more faults to be corrected somewhere in the future. Instead of setting up the communication and learning curve characteristic to Lean implementation, the implementation of TPTC in the case project made the construction process, which by nature is creating faults and vicious cycle of waste, controllable and manageable for the main contractor. Nevertheless, the project was considered to be successful, as the throughput time was successfully reduced by $30 \%$, and the targets concerning customer satisfaction, quality and the financials, were met. The challenge with drying times and the resulting need for daily changes to the weekly plan could have been disastrous, but thanks to the aid of digital tools, the change management was very efficient on-site. The common situation awareness made the decision making very fluent and effective as the required information for correct decisions was available in real-time and via mobile devices. The deviations in quality management and the delta between the original takt plan and actuals require further study and suggest that situation awareness in combination with real-time digital tools can turn a doomed project into a manageable one.

Takt production enhanced with digitalised scheduling and quality management applications provide an efficient tool for foremen and site manager by which the production team was able to complete the project even though the tolerance management problems were severe and lead waste constantly present. The production team, both the personnel of main contractor and trades, benefitted from the situation awareness information, and they were able to finalise the project in time by using TPTC as a tool for re-planning the order of tasks and assigning the tasks for a most efficient way to reduce the throughput time. The digital footprint of the project reveals that there is a significant potential for increasing productivity by removing the making-do/task diminishment as a lead waste of TPTC. However, the TPTC implementation was not successful as such and the project failed in implementing the LPS as a method for identifying and reducing the number of faults and quality problems during the project. The digital footprint was not adequate for supporting the project team for identifying the vicious cycle of waste. Further research must be conducted for data gathering, realtime analysis and further visualisation for providing valuable knowledge for TPTC teams and help them implementing the LPS and especially the make-ready planning as a part of TPTC project. 


\section{REFERENCES}

Binninger, M., Dlouhy, J., Müller, M., Schattmann, M. and Haghsheno, S. (2018). "Short Takt Time in Construction - a Practical Study." Proc. of the 26th Ann. Conf. of the Int'l Group for Lean Construction. Chennai, India

Chauhan, K., Peltokorpi, A., Seppänen, O. and Berghede, K. (2018). "Combining Takt Planning With Prefabrication for Industrialized Construction." Proc. of the 26th Ann. Conf. of the Int'l Group for Lean Construction. Chennai, India

Dlouhy, J., Oprach, S. and Binninger, M. (2018). Using Taktplanning and Taktcontrol in Production Projects - Comparision of Construction and Equipment Phases. Proc. of the 26th Ann. Conf. of the Int'l Group for Lean Construction. Chennai, India

Frandson, A., Berghede, K. and Tommelein, I. D. (2013). "Takt time planning for construction of exterior cladding." Proc. of the 21st Ann. Conf. of the Int'l Group for Lean Construction. Fortaleza, Brazil

Love, P., Edwards, D., Irani, Z., \& Walker D. (2009). Project Pathogens: The Anatomy of Omission Errors in Construction and Resource Engineering Project. IEEE Transactions on Engineering Management, vol. 56, no. 3 August 2009

Milberg, C. and Tommelein, I. D. (2004). "Tolerance Mapping - Partition Wall Case Revisited." Proc. of the 12th Ann. Conf. of the Int'l Group for Lean Construction. Helsingor, Denmark

Ohno, Taiichi. 1988. Toyota production system. Productivity Press, Cambridge, MA. $143 \mathrm{p}$.

Talebi, S., Koskela, L., Shelbourn, M. and Tzortzopoulos, P. (2016). "Critical Review of Tolerance Management in Construction. " Proc. of the 24th Ann. Conf. of the Int'l Group for Lean Construction. Boston, MA, USA.

Zhao, J., Olivieri, H., Seppänen, O., Peltokorpi, A., Badihi, B. \& Lundström, P. (2018). Data Analysis on Applying Real Time Tracking in Production Control of Construction. 2017 IEEE International Conference on Industrial Engineering and Engineering Management (IEEM). DOI: 10.1109/IEEM.2017.8289956.

von Moltke, H. (1871) Über Strategie. Cited from Militārische Werke (1890), Band 2, Teil 2. Mittler \& Sohn Berlin 
Alhava O., Rinne V., Laine E, and Koskela L 